\title{
Hacer (la) nada. En torno a «Un homme qui dort» de Georges Perec
}

\author{
Do nothing(ness) \\ Around «Un homme qui dort» \\ of Georges Perec
}

\author{
ALBERTO RUIZ DE SAMANIEGO \\ Universidad de Vigo (España)
}

Recibido: 17-XI-2015 Aceptado: 8-XII-2015

\section{RESUMEN}

En este artículo se aborda la novela y el film de Georges Perec que llevan por título Un homme qui dort. Se establecen las conexiones filosóficas y literarias que la narración traza, la relación con el concepto de vida cotidiana tal como lo manejaron los Situacionistas o Henri Lefebvre, la búsqueda de la novela sin tema característica de la Modernidad y el concepto del formalismo ruso de extrañamiento como procedimiento de trascender y superar la experiencia instrumentalizada de la realidad.

$$
\text { PALABRAS CLAVE }
$$

PASIVIDAD, VIDA COTIDIANA, EXTRAÑAMIENTO, APATÍA, FLÂNEUR

\section{ABSTRACT}

In this article, both the novel and the film Un homme qui dort by Georges Perec are approached. The philosophical and literary connections traced by the narrative are established, as the 
relation with the concept of everyday life as handled by the Situationists or Henri Lefebvre,as well as the search for a novel without a characteristic theme, a usual feature in Modernity and the concept of Russian formalism of estrangement as a procedure to transcend and overcome the instrumentalized experience of reality.

\section{KEYWORDS}

PASSIVITY, DAILY LIFE, ESTRANGEMENT, APATHY-FLÂNEUR

Hay algo sagrado en todo ser

que ignora su propia existencia, en toda forma exenta de conciencia. Aquel que nunca ha envidiado al vegetal, ha pasado a un lado del drama humano.

E. M. Cioran, La caída en el tiempo.

Si cada yo es padre y creador de sí mismo ¿por qué entonces no puede ser también el propio ángel exterminador?

Jean Paul.

LA NOVELA UN HOMBRE QUE DUERME se abre con una cita de un aforismo de Franz Kafka, perteneciente a las Consideraciones acerca del pecado, el dolor, la esperanza y el camino verdadero. Dice así: «No es necesario que salgas de tu casa. Quédate en la mesa y escucha. Ni siquiera escuches, espera solamente. Ni siquiera esperes, quédate completamente solo y en silencio. El mundo se te ofrecerá para que lo desenmascares, no puede hacer otra cosa, extasiado, se prosternará a tus pies» (Perec 1989). ${ }^{1}$ En cierta manera aquí nos aproximaríamos, como principio, a un viejo pensamiento pascaliano, que sin duda Kafka y Perec conocían: la desgracia del género humano consiste en que el hombre es incapaz de quedarse quieto en una habitación. Como vemos, un postulado de inmovilidad y encastillamiento radical que tendría su culminación, por ejemplo, en la jaula en que reposa sin solución ni destino el artista del hambre, en el caso de Kafka, y, en una dimensión histórica, en tanto que decidida voluntad de poder planetario, en el palacio, acaso, de El Escorial. ${ }^{2}$

1 Seguimos la edición de la versión española: Un hombre que duerme, trad. de Mercedes Cebrián, Ed. Impedimenta, Madrid, 1989. A partir de ahora, la novela se citará como UHQD.

2 Mansión que es a la vez fortaleza y monasterio, casa del rey del cielo y de España, lugar macizo, mineral, lleno de fuerza y soledad. He ahí el lugar del que salían todas las órdenes de un monarca que, justamente desde la austera constricción de su morada -casi recluso, un melancólico de primera hora- gobernaba el mundo. 
La comparación tal vez no sea tan caprichosa como parece; de hecho más bien nos abre una vía -real- para entender lo que Perec se trae entre manos. Como sugiere Ramón Gaya, el carácter de El Escorial no es expresivo, y por ello algunos comentaristas lo encuentran frío: «gran parte de su aristocracia, de su orgullo, de su deber, de su penitencia es eso: no expresar». Todo en él es fijeza, mero estar: «Ser inmóvil es aquí una pasión» (Gaya 2010, 362). El protagonista de Perec, en cierto modo él también un monumento de sí mismo, trata de alcanzar este destino de íntegra presencia a-pática, libre de toda finalidad o acción, de cualquier determinismo; puro dasein, diríamos: estar-ahí, pero absuelto de toda relación, como dándose por descontado. Y esto es algo ciertamente nada sencillo; encarnar la significancia blanca y rígida de la noexpresión.

En verdad, se trata de un extraño objetivo, donde se suspende y se supera la oposición misma de lo activo y lo pasivo, tal como, por caso, interpretaba Hegel, en sus lecciones de estética, el famoso cuadro de Murillo con los dos niños mendigos. Suponía para él la encarnación del ideal, porque esos muchachos no hacían nada. Extraño ideal, efectivamente, en donde el hombre empírico reina por anulación. Tal vez el protagonista de la novela de Perec aspire a ser -a su modo paradójico: oximorónico- algo parecido a un héroe wagneriano, vuelto un semidiós justamente por su apartamiento de la acción. Se da aquí un fulgor de poder incongruente, como el que también ha notado Jacques Rancière cuando medita acerca de una noción que tiene claramente que ver con esta esfera de la potencia: la de huelga general. Supone -dice Rancière- «la expresión acabada de la colectividad obrera combativa», pero al tiempo, la «equivalencia ejemplar de la acción estratégica y la inacción radical» (Rancière 2015, 16).En todo caso, esta referencia kafkiana del comienzo del relato no puede, desde luego, ser casual: en realidad, no se me ocurren dos escritores más centrados en su lugar de trabajo -como si de una guarida, un bunker o un scriptorium medieval se tratase- ${ }^{3}$ que Kafka y Perec, tal vez con la excepción del maestro de ambos: el gran solitario de Normandía: Gustave Flaubert.

Kafka, como Perec, adoraba la escritura de Flaubert: fría, tersa, impersonal; lograda - como sabemos- con el máximo esfuerzo del día a día. De hecho, es conocido que el checo soñaba a menudo que se encontraba en una sala grande llena de gente y desde el podium leía en voz alta, íntegra y sin interrupciones, La educación sentimental. Era, también, una vez más, otra fantasía

3 Sugiero únicamente, en este sentido, la fascinación reiterada que Perec manifiesta por el cuadro de Antonello de Messina donde vemos a San Jerónimo en su estudio, parapetado frente al mundo con todos sus útiles de escritura, como en cueva anacorética prefabricada. En cierto modo un arca de Noé donde el escritor se protege del naufragio del mundo, del naufragio que es el mundo: tal vez para salvarlo o al menos dar testimonio de él...por medio de lo que se escribe, de lo que está escrito, y escrito queda. 
de poder, el deseo de dominar el mundo o a los demás con la única arma que le proporcionaba una superioridad a su altura, es decir, con la palabra. En el caso del protagonista de la novela de Perec es aun más radical la fantasía de dominación: ser soberano sobre el mundo ya no por la palabra o la lectura, sino por el mutismo, la pasividad, la indiferencia. Él, como el gran ayunador kafkiano, es un supremo artista de la privación, aún más: alguien que brilla -humano sol negro- por su ausencia.

Perec tuvo siempre muy claro que éste era el trasfondo de su relato: un inventario de la vacuidad, o -como él mismo apuntó en alguna entrevista- la tentativa de agotar todos los lugares retóricos de la indiferencia, de la misma manera que Las Cosas había sido el intento de agotar todos los lugares retóricos de la fascinación. ${ }^{4}$ Lo que en Las Cosas era el sueño voluptuoso-y patético-de identificarse con los objetos de consumo como una forma de superarse, o de sublimarse y escapar de uno mismo, ahora, sin embargo, se ha convertido en la anulación de todo, incluida la propia singularidad. Un hombre que duerme constituye por tanto el retrato en negativo, el envés excavado como un hueco sobre el suelo eufórico de la sociedad consumista de Las Cosas. ${ }^{5}$ El reverso de la fascinación, pero no su contrario. De la misma forma que el olvido no es lo contrario del recuerdo, sino su revés. La indiferencia, pues, pero apurada hasta su agotamiento: llevada a la totalidad. Un hombre que duerme es el relato de una anacoresis, y también un tratado de anestética.

Debemos, por tanto, entender antes que nada el término vacuidad también en su puro sentido etimológico. Aquel, por ejemplo, que nos ofrece De Quincey, en una de sus notas de las Confesiones de un inglés comedor de opio, un texto que constituye un verdadero modelo, por cierto, de narración de la deriva en la acepción situacionista: «el sentido tradicional de vacuus es despreocupado, libre de cualquier carga de ansiedad; así vacuitas será el resultado de la inmunidad contra el robo. Pero me inclino a comprenderlo en el sentido de libre de la carga de la propiedad, en cuyo caso el sentido de vacuitas sería la

4 Esto es, y como apunta el propio Perec: de mostrar «todo lo que se puede decir a propósito de la indiferencia». En la estela por cierto de uno de sus primeros maestros: RolandBarthes. El Barthes de las Mitologías, que tan hondo influjo había ejercido en la redacción de Las Cosas, y del que precisamente se realiza un desvío literario en un fragmento de UHQD: el momento -memorable- en que el protagonista engulle, digámoslo así, el grado cero de un bistec de ternera. También del Barthes que por entonces, años 64-65, impartía el seminario «Recherches sur la rhétorique» en la École pratique des hautes études. Para la relación entre Las Cosas y Un hombre que duerme, cf. Roman 20-50. Revue d'étude du roman XXe siècle. Georges Perec. Les Choses et Un homme qui dort, $\mathrm{N}^{\circ} 51$, juin 2011, especialmente el artículo de Jean-LucJoly: «Des choses qui dorment», pp. 11-26.

5 La versión fílmica del relato va a dar gran relieve visual a esta idea de la reversión en negativo. 
causa de esa inmunidad» (De Quincey 2001, 409; las cursivas son nuestras). Es este hecho de aparecer el personaje de la novela vaciado de todas sus atribuciones lo que hace precisamente de su vivir su monumento. Lo que lo vuelve figura enigmática pero ejemplar del entumecimiento y la somnolencia, de la inexpresividad y la desafección, al modo, es cierto, de El Escorial y su rey, al modo de una esfinge.

En este punto, y en oposición a posibles precedentes existencialistas ${ }^{6}$ del relato, como La Náusea o El extranjero -o, aun antes, El fuego fatuo de Pierre Drieu la Rochelle, incluso el Malte Laurids Brigge de Rilke-, hay un rasgo sintomático en el personaje de Perec: a éste no le interesa abrir el problema de una pretendida -o presupuesta- profundidad subjetiva. Aquí la introspección y toda idiosincrasia personal son negadas, toda subjetividad rechazada. Así, el comportamiento del protagonista no responde a ninguna referencia filosófica, sociológica, psicológica o existencial. Él se muestra efectivamente inmune a todo ello. De este modo, y frente al espejo, por ejemplo, el personaje no sufrirá las miserias arbitrarias de la introspección, pues se trata, efectivamente, de un individuo liberado de toda propiedad. Estamos ante alguien que no coincide ya con nada, ni siquiera consigo mismo; habiéndose convertido casi en el sueño rígido de un objeto sobre el cual toda inquisición se desliza, vana, inocua. Un ser, en consecuencia, libre, dispensado: inmunizado. Habrá de ser precisamente el hecho de que el espejo tan sólo revele una ausencia la fuente segura de una severa virtud, del acceso a una potencia. Aquélla que, descargada de los pesares de la autoconciencia -y también de la autoalienación - ha roto, de forma que se quiere definitiva, con el característico laberinto especulativo que se despliega cansino en interminables oscilaciones y reconsideraciones sobre uno mismo.

Diríamos, más bien, que la personalidad de este hombre es puramente teórica, de papel, una proyección de infinitas lecturas (las de él mismo, las de Perec). Por ello, y por buscarlo en algún sitio, se manifiesta como el resultado de un cruce literario en donde estarían bastantes autores: Kafka, Melville, Joyce (Stephen Dedalus precisamente como encarnación del hombre laberíntico), Barthes, Blanchot, Camus y Sartre, claro; desde luego Proust. Como si, en un escamoteo característico del escritor, la propia experiencia biográfica sufrida por Perec -el paso por un colapso depresivo a los 20 años - fuese desviada, oscurecida y, finalmente, resguardada por una pirámide textual y de personajes que, por decir así, guardan lazos de familia -Roquentin, Meursault, Dedalus, Bartleby, Joseph K-. Seres que funcionan como figuras de identificación -y de emancipación-que, al cabo, disimulan y se interponen -o desvían, como hacen

6 No puedo dejar de recordar una broma que Perec incluye a costa del existencialismo, en un momento en que el protagonista de $U H Q D$ cubre mentalmente un crucigrama. El planteamiento dice: «su existencia precede a la esencia». La resolución: «trementina» $(U H Q D, 57)$. 
por ejemplo los muñecos o los fetiches de un conjuro, o los heterónimos- el propio trauma personal sufrido por el escritor.

Un hombre que duerme es una narración, por lo demás, donde ni siquiera el sentimiento del absurdo interviene, pues en este caso no aflora opacidad alguna; ninguna toma de conciencia de su biografía particular o de su contingencia. Ningún sentimiento tampoco de culpabilidad. Más bien encontramos el espesor pertinente del personaje bajo una luz precisamente proustiana, esto es: en la contradicción entre un sujeto dotado de hipersensibilidad y su extrema voluntad de anulación. De haber experiencia, se trata de algo de carácter esencialmente somático, en la medida en que en él o a través de él son solicitados muy diferentes registros sensoriales: la observación, sin duda, pero también las visiones que surgen en el fondo de las pupilas cerradas, las sensaciones cromáticas -el rosa de la palangana de plástico-, auditivas -esa gota de agua que acompasa su morada o las campanas que limitan su calle-o incluso las gustativas: el sabor del café demasiado azucarado. Se trata de un tipo de experiencias fragmentarias, radicalmente materiales y sin unificar; sin ninguna progresión o cohesión: allí no hay lugar para la memoria o el sentido. Quizás su interés más bien circula, como diría Debord, en torno a la cosificación (Debord 1994, 22). En relación, por ejemplo, con una crítica de la separación a la que el hombre es sometido en la sociedad de consumo. Una crítica de «las contradicciones de la vida material, alrededor del conflicto que existe entre las fuerzas de producción sociales y las condiciones sociales» (Sur le passage de quelques personnes à travers une assez courte unité de temps). Esto es: centrada en el eje de la vida cotidiana y las posibilidades de liberación que allí acaso se generan.

El punto en común de ambos escritores, Perec y Debord -tan semejantes en algunos aspectos: el gusto por el desvío literario y la cita encriptada, la fricción o la desincronización entre lo que el texto dice y lo que la imagen muestra, la puesta en cuestión incluso de la imagen filmada por la palabra o el comentario, la observación de la ciudad como un laberinto y un enigma que hay que resolver, la atención a lo infraordinario y el acceso democrático a lo real concreto, la experimentación, en fin, de la deriva-es, sin duda, Henri Lefebvre. De hecho, podríamos ver $U H Q D$ como la elaboración radical del concepto que de vida cotidiana aportó Lefebvre: «lo que queda cuando se sustraen de lo vivido todas las actividades especializadas» (Debord 1999, Vol. 1, 188). En cierto modo, el protagonista de $U H Q D$ cifra su objetivo en esta sustracción, que le permitiría liberarse-liberar todos los sentidos-de cualquier funcionalidad o utilitarismo, de toda convención, de la socialización establecida. Una sustracción que habría que situar bajo el dictado de la depresión: alguien incapaz de dominar su vida o de comprender la realidad decide simplificar al máximo toda relación, esquematizando y reduciendo la existencia a una mera articulación corporal. 
Pero, no lo olvidemos, manteniendo el espíritu de totalidad. Aquí radicaría su voluntad-extrema- de poder.

También fue Lefebvre quien sostuvo que «el inventario de lo cotidiano va acompañado de su negación por el sueño, por lo imaginario, por el simbolismo; negación que supone también la ironía frente a los símbolos y a lo imaginario» (Lefebvre 1972, 9). Tal vez por ello, por ejemplo, todo comienza con una recapitulación irónica, por lo que niega, de la figura del durmiente, tal como se construye en un escritor que continuamente sobrevuela el imaginario de Perec: Marcel Proust. Un Proust cuyo universo, como es sabido, es particularmente rico en rememoraciones, en afectos sensibles y registros sensoriales, en imágenes y recuerdos del ensueño. Un Proust, en fin, como modelo que en Perec siempre se halla sometido sin tregua a deconstrucción, a vaciado, a détournement. Si queremos, el protagonista de $U H Q D$ se ha pensado eliminando todo lo que caracteriza al personaje proustiano: la vida social, la vida afectiva, la voluntad de actuar, el registro de la memoria y del pasado, los lazos de familia. No sería más que un blanco, una inmensa carencia en el cuerpo social, y en el narrativo. En este sentido, no se puede obviar que el título del libro de Perec -y su comienzo- procede de una sentencia muy conocida de Proust, que aparece también en el inicio mismo de la Recherche: «Un hombre que duerme tiene en torno suyo el hilo de las horas, el orden de los años y los mundos») (Proust 2004, 34). ¿Lo tiene verdaderamente en el relato de Perec?

Aquí radicaría, es cierto, su aspiración de poder. Pero también su proyecto, digamos, artístico, en la misma medida en que el ayunador profesional de Kafka es considerado un artista del hambre, y el mejor tal vez que en el mundo exista, tal como acredita el narrador del relato. Un maestro de Proust, Henri Bergson, en Les donnéesimmédiates de la conscience, sugiere, en este sentido, una vía interpretativa muy fértil. A juicio de Bergson, cada artista libera el sentido particular en el que desarrolla su trabajo: el pintor, libera la visión, el músico, la audición: el gran artista sería aquel que tuviera todos los sentidos liberados respecto del utilitarismo. Al hallarse completamente libre de toda solución convencional o instrumental habría de ver el mundo o, mejor, tendría al mundo de un modo como jamás nadie lo tuvo. Totalmente y en su profunda realidad. He ahí el designio de nuestro hombre. Proyecto que al tiempo es existencial y estético. Desde esta última perspectiva, sin duda nos situamos aquí cerca de la teoría del extrañamiento que Sklovski formuló de la siguiente manera: podemos reconocer un fenómeno artístico cada vez que un procedimiento ha sido intencionadamente sacado del ámbito de la percepción automatizada. El famoso ensayo de Sklovski, luego incluido en su Teoría de la prosa, lleva el título significativo - algo perecquiano- de «El arte como procedimiento». Allí manifestaba la confianza en la capacidad de revelación que lo estético posee, a través de los procesos de desfamiliarización y deformación de la percepción 
habitual de las cosas. Un convencimiento que se apoyaba precisamente, y de nuevo, en Bergson. En la idea de que entre la conciencia humana y el mundo se interpone, debido a la rutina de la vida cotidiana, un velo espeso que el arte ha de rasgar, permitiendo a los hombres ver, en una visión depurada y siempre nueva, la naturaleza al fin desocultada de los seres y de los objetos (Sklovski, en Todorov 1965, 76-97 y Ginzburg 2000, 15).

Junto con Flaubert, el otro referente de juventud de Perec fue Lukács, aquél que había catalogado La educación sentimental como la «novela psicológica de la desilusión». Fréderic Moreau, el protagonista de la novela de Flaubert, tiene un alma que supera en amplitud de metas al mundo que le toca vivir. Y, tal vez por eso, hace de su existencia algo inacabado. La educación sentimental es, como casi todos los relatos kafkianos, como Un hombre que duerme, el relato de un inmenso desengaño. De hecho, Kafka veía en Flaubert el fundador y al tiempo la culminación de aquella literatura moderna de la soledad y de la carencia a la que él mismo se sentía pertenecer. Puede que Perec, el huérfano, el sociólogo de la generación del consumismo, haya visto allí lo mismo. Pero hay en La educación sentimental otra cosa, que ni Kafka ni Perec podían dejar de admirar ni de advertir: la gracia indecible e inexorable que recorre sus páginas. Esa pura e inmaterial forma musical que aletea en la prosa por encima de todo desvanecimiento, como una música perfecta hecha de nada, también desde la nada. Esto es muy conocido: Flaubert aspiraba a escribir, como decía en 1852 aLouiseColet, su amante, un libro sobre la nada: «un libro sin apoyos exteriores, que se sostuviera solamente por la fuerza intrínseca del estilo, como la tierra se mantiene en el aire sin necesidad de sostén; un libro casi sin tema-sujeto, o al menos cuyo sujeto fuera, si fuese posible, casi invisible» (Flaubert 1989, 142). He aquí un proyecto: moderno entre todos lo proyectos, pues, tal como sugiere Ernst Jünger, en Sobre la línea, quien no ha experimentado sobre sí el enorme poder de la Nada y no ha padecido su tentación, conoce bien poco nuestra época ${ }^{7}$ (Rancière 2015, 15).

Así pues, nada menos que un libro a partir de un tema o un sujeto sin propiedades. Un libro sobre la nada o construido en el vacío. Esto se cumplirá, por ejemplo, en el Libro del desasosiego de Fernando Pessoa. Sin cumplirse del todo, pues la nada es por definición como el arte del ayuno, lo que no tiene límites y por tanto lo que condena a lo infinitamente inacabado. La obra es un fragmento que siempre requerirá de tiempo, de más tiempo para cumplirse en un final imposible que se proyecta al infinito. Fragmento atrapado entre el ahora y el todavía no, para siempre fuera de tiempo. No obstante, allí vemos a

7 De hecho, ya el mismo Rousseau, con su voluntad de farniente y ensoñación, celebra la pasividad del contemplador e inaugura con La nueva Eloísa la larga serie de las novelas sin acción, dedicadas a eso que Borges llamó «lo cotidiano insípido y ocioso». 
un narrador, Bernardo Soares, despojado por completo de toda acción exterior, de toda vida empírica. En favor de una interiorización en que el sujeto y toda realidad se anulan en un (in)espacio nomádico y espectral, de ensoñación pura. La vida de Soares es pálida y frágil como el papel, es de papel. De hecho - como apunta el propio Soares - sobre su vida anodina e insignificante - «inexistente», llega a escribir-sólo es posible realizar una autobiografía sin hechos, una historia sin vida. Eso sí, todo en una prosa extremadamente nítida, preciosista y precisa: impresionante en su penetración, musicalidad y rigor. ¿No es este también el caso del protagonista y de la prosa de Un hombre que duerme?

Soares es un empleado de escritorio -como su precedente más famoso: Bartleby, y como el propio Pessoa-. Su libro quiere ser, en declaración del propio Soares, una experimentación y una analítica del tedio, como lo quiso ser el de Perec. El cansancio, el tedio, la abulia o la indiferencia favorecen, es claro, el desvío respecto a toda percepción estable o heredada de la realidad. La indiferencia o el hastío se separan y quiebran cualquier instalación fija y delimitada en el mundo. Como bien supieron Cage o Duchamp, estas (des)afecciones se vuelven capaces de abrir la posibilidad de experiencias o sensaciones inéditas, abismos infinitesimales, agudas (auto)percepciones que crecen en los huecos por donde uno (des)aparece y resuena. Modos, en definitiva, de neutralización de toda realidad signada, ofrecida, preparada, identificada.

Poco después de publicar La educación sentimental Flaubert, al releer a Goethe, exclama: «He aquí un hombre, pero él lo tenía todo, todo para sí» (Flaubert, 1989, 226). Flaubert, por el contrario, no tenía nada, ni siquiera a sí mismo. Tampoco, pues, ese sentimiento compacto de la posesión de sí; estaba solo, y, mirándose al espejo como hace el héroe de la novela de Perec, se soltaba a reír y sentía escaparse la vanidad de la vida en un enigma indescifrable: «Je suis mystique et je ne crois à rien». Nuestra verdad -ya lo ha sugerido Claudio Magris- no es aquella de Goethe que tenía todo, sino aquella de Flaubert, que no tiene nada. Frédéric Moreau es nuestro yo anónimo, el hombre sin cualidades especiales, capaz de amor pero también de indiferencia e insensibilidad. También esto lo notó agudamente Lukács, Flaubert ha cumplido el milagro de dar sentido a la insensatez de la vida, de evocar todo aquello que ella quita luego de haberlo prometido; de narrar la odisea de los hombres modernos expulsados del paraíso terrenal - de una tierra de valores duraderos- y abandonados a la fugacidad. Hombres que han de echar a andar, en los territorios de la culpa-que es la Historia y es el mundo- a partir de esa primera expulsión ${ }^{8}$.

8 Acaso por esto mismo el acto de caminar está a menudo asociado con el castigo, por ejemplo en el infierno de Dante. Y el vagabundaje que practica el protagonista de $U N H Q$ ha sido tantas veces penalizado, especialmente en nuestras sociedades sedentarias y estamentadas. 
Hablamos, pues, también, de hombres abandonados a la finitud, a la fugacidad: hombres cualquiera, hombres que marchan. Ellos son nuestros semejantes, nuestros coetáneos. Multitudes urbanas, modernas y erráticas que describe, por ejemplo, el conocido poema de T. S. Eliot: «ciudad irreal, / bajo la niebla parda de un amanecer de invierno, / una multitud fluía por el Puente de Londres, tantos, / no creí que la muerte hubiera desechado a tantos. / Se exhalaban suspiros, breves y poco frecuentes, / y cada cual llevaba los ojos fijos ante los pies» (Eliot 2001, 57-60). Paseantes frágiles, casi fantasmas reducidos a meras siluetas en la inmensidad gris de la metrópolis. Son también así, a menudo, los personajes vagabundos de Beckett, «formas semidesvanecidas y mudas, caminando a grandes pasos laboriosos, a través de la espesa nieve» (Beckett 1989, 65). Como esa figura que obsesionaba a Giacometti, la del ser humano solo, erosionado y prácticamente sin contornos, en la modestia radical de su situación elemental y dudosa. Mero aparecido como forma exánime de «ser en el mundo», casi en el límite pardo o gris del fenómeno perceptivo. Decididamente: flotando entre el ser y el no-ser: hombre-cesura: hombre perdiendo el equilibrio 9 (Giacometti 1990, 325). Lefebvre: «No diremos nada nuevo a nadie si recordamos que el Sujeto se ha esfumado, que ha perdido sus débiles contornos, que ya no parece ni siquiera una fuente, ni siquiera un flujo. Y con él, y antes de él, el carácter, el personaje y la persona. ¿Lo que prima? El Objeto. No en la objetividad (que no tenía sentido más para, por y ante el sujeto), sino según la objetalidad [sic] y casi como forma pura» (Lefebvre 1972, 15). Así pues, lo que ahora toca para estos sujetos menguantes, hombres cualquiera sometidos al imperativo del objeto, son objetos cualquiera: «Si quiero escribir hoy, quiero decir "escribir literariamente", tomaré un objeto cualquiera. Intentaré su descripción minuciosa; permaneciendo en el nivel de lo sensible, que tomaré voluntariamente por lo concreto, voy a clasificar, inventariar, este objeto tomado de lo cotidiano: un cubilete, una naranja, una mosca. ¿Por qué no esta gota de agua que se desliza por el cristal? Puedo escribir una página, diez páginas, a propósito de esta gota. Va a representar para mí lo cotidiano, eludiendo la cotidianidad; va a presentar el tiempo y el espacio o el espacio en el tiempo; va a convertirse en mundo sin dejar de ser una gota que se desintegra» (Lefebvre 1972, 15).

Presentar el espacio en el tiempo puede que signifique tratar de imponer la espacialidad como dominio -incluso la objetualidad-sobre la duración.

9 Tal es el nombre de una de las obras del escultor suizo. Incluso, de creer a Simone de Beauvoir, algo parecido sucedía con el propio escultor: «Hubo una época -recuerda la Beauvoir- en la que, cuando andaba por la calle, tenía que asegurarse de la solidez de los muros de las casas con las manos para resistir al abismo que se había abierto a su lado. A veces también tenía la impresión de que nada tenía peso: en las calles, en las plazas, la gente flotaba en el aire». 
Suprimir el tiempo al promover una clasificación, un inventario exhaustivo, asfixiante: agotador de lo sensible concreto, impertérrito. Si atendemos a estas premisas, vemos que, en cierto modo, lo que se propone Perec al redactar esta enigmática novela es que nada acontezca, que la nada misma sobrevenga. Suspender el devenir. Y entonces la voluntad de poder de que se habla tendría más que ver con un acceso a una especie de subeternidad fuera ya de la Historia en la que el protagonista vive, por decir así, hechizado por el negativo de sí mismo. Mineralizado, en estado vegetativo o larval, sumergido en lo indiferente o en lo gris como una piedra o un bloque de hielo o un giacometti. Como si se tratase de la bella durmiente. Dormir, es cierto, podría ser un pasaje que nos libere hacia esta subeternidad, esa vacuitas:

No ser ya propio, no encontrarse ya propiamente en la relación de la propiedad de sí, sino, de manera más profunda y oscura, ser a sí de tal modo que la cuestión de lo «propio» tienda a borrarse (¿soy yo en verdad yo?, ¿soy efectivamente lo que soy, lo que tengo que ser?): esto equivale a dormir, pues exige la disipación del interrogante y de la inquietud que lo anima. «QQuién soy?» se desintegra en la caída del sueño, pues esta caída me lleva hacia la ausencia de preguntas, hacia la afirmación incondicional e indudable -ajena a cualquier régimen de duda, a toda condición de identificación- de un ser a sí que no sufre ningún despliegue, ningún análisis de su estructura. Un ser que no se hace acreedor a una problemática de la «relación consigo» ni de la «presencia a sí»: ni relación ni presencia deben hacerse valer en este punto (Nancy 2007, 24-25).

Aunque, de hecho, si observamos por ejemplo el film de Perec con detenimiento, comprobaremos que este hombre jamás aparece durmiendo. Convertido en la sima y la inmersión de sí mismo, diríamos más bien que dormita o que es un durmiente con los ojos abiertos. Que está en letargo, como cuando se habla de un volcán que está dormido, en ese estado - pleno de su propia vacuidad, adormecido en el reposo- en el que nada parece estar sucediendo. Todo se vuelve indistinto en esa distensión que tiene que ver, indudablemente, con el motivo del sueño, con el hundimiento en la desconexión, la lasitud, el tedio, el abandono, el adormecimiento, la deriva. Allí el tiempo se ha retirado y ningún instante o signo de vitalidad se muestra a nuestros ojos.

El hombre que duerme vive, pues, en la ilusión de separarse del tiempo, y en ello radicaría su poder o su inmunidad, y su ilusión misma: en creer haberlo vencido, al alejarse de su influjo; de la misma manera que el artista del hambre, por ejemplo, tacha el pasado en su propio cuerpo, al tratar de borrar las huellas de lo que su organismo ingirió. Todo el peso del arte de ambos se halla en la pérdida. Arte magro. Su renuncia, su abandono evidencian una retirada de la intencionalidad en cualquiera de sus formas. Renuncia a la intención y a la atención, a la tensión y a toda expectativa. Todos los proyectos 
han desaparecido, se desintegran las previsiones y los cálculos, los objetivos, en aras del logro de la ausencia.

Descubres, a veces casi con una especie de embriaguez, que eres libre, que nada te pesa, ni te gusta ni te disgusta. Encuentras, en esta vida sin desgaste y sin otro estremecimiento que esos instantes suspendidos que te procuran las cartas o ciertos ruidos, ciertos espectáculos que te proporcionas, un bienestar casi perfecto, fascinante, a veces henchido de emociones nuevas. Experimentas un reposo total, estás, en cada momento, resguardado, prometido. Vives en un paréntesis venturoso, en un vacío lleno de promesas del que no esperas nada. Eres invisible, límpido, transparente. Ya no existes (UHQD, 70-71).

Tal existencia aspira sin duda al estatuto de un dios, el gran sujeto que vive en su santa segregación, el kadosh-el separado-del Levítico; el que existe puro por su separación, precisamente. Como ha apuntado Jean-Luc Nancy: «En el extremo del sujeto puro todos los predicados están negados (así sucede con el Dios de las teologías negativas y de los místicos: tanto más archi-esencialmente divinos cuanto más despojados de toda cualidad o propiedad)» (Nancy 2007, 113). Va a resultar verdad lo que sostenía Spinoza, que Dios es el ens realissimus: la realidad por excelencia, pues no depende de ninguna otra cosa. Esta es la aspiración del hombre que duerme, distante de toda relación, protegido de toda inquisición y fenomenalidad. Hombre absuelto, o la condición humana en huelga general, exenta de todos los juicios, los saberes y las perspectivas. Concentrada en sí misma sin ninguna determinación, en su unidad completamente simple y sin diferencia, sin atribución, sin propiedades. Presencia de una ausencia, el gran evadido social; su ocultamiento fenomenológico busca la rendición de todas las intenciones y las miras, así como de los cumplimientos de sentido. Tal fervor por una buscada e insistente inexistencia habría de concederle una extraña paz, que tiene que ver, es de esperar, con la posesión del mundo. Un mundo que sería, acaso, el de la universalidad en la no diferencia. Mundo de necesaria insignificancia y apatía, que confina también, por ello, con la oscuridad, la nulidad y el silencio. Por eso a nuestro hombre le conviene la noche y la uniformidad del sueño o el letargo. Es el mundo, quizás, de la democracia radical de lo infraordinario, también el que propiciaría la poesía hecha por todos en que creyera Lautréamont y con él los Situacionistas. Un mundo donde toda la gente participaría en la igualdad como de sueño colectivo de lo común, lo inmemorial, lo indistinto. Es el mundo que luego se perfilará en Je me souviens, por ejemplo.

El misticismo sufí sitúa el máximo grado de espiritualidad en aquel que está muerto para sí mismo; el que ha escapado de las ataduras de las características humanas y realmente ha alcanzado a Dios. Este es llamado, de forma significativa, un muerto que anda. Aunque hay una diferencia, sin embargo, 
entre estar separado y estar muerto. Una diferencia que se sitúa en relación con el tiempo, justamente, y que comentó el propio Sartre en El ser y la nada: estar retirado (être mis à la retraite) condena a no tener otra cosa que pasado. Para quien está muerto, por el contrario, el pasado no existe. Pero la experiencia desengañada del retirado, de quien vive en el vacío de toda propiedad es, fundamentalmente, la del narrador moderno. Esto es: aquél que, aun estando separado, no tiene sin embargo historia, o ya no tiene historia: es incapaz de trabajar o activar ese pasado porque en el centro de su arte está la nada, o el vacío. En este sentido, el narrador moderno, el que nace por ejemplo con Flaubert y se cumple de manera inquietantemente esplendorosa con Kafka o Pessoa, es un muerto-vivo, alma errante que vaga sin remisión por los agujeros de la existencia y del texto. Muerto-vivo tal como lo es, por ejemplo, el cazador Gracchus («Aquí estoy, muerto, muerto, muerto», llega a afirmar). Este lugar critico de la enunciación, lugar (del) negativo, es el que, con tono a menudo irónico tomará Beckett ${ }^{10}$, o el que problematiza toda la enunciación blanchotiana. Ambas perspectivas son las que heredará a su vez Perec.

Pero esta serie de huellas con las que el autor hace prestidigitación literaria no está lejos desde luego del trauma biográfico -como decíamos-. Bartleby-lo ha confesado Perec en alguna entrevista- tiene para él algo de particular. Algo que en palabras del escritor está contenido «en ese sentimiento problemático: la extranjería o la extrañeidad, el alejamiento, lo irremediable, lo incompleto, la pieza que falta, el vacío, etc.» De algún modo, ha confesado Perec,

yo soy extranjero en relación a algo de mí mismo: en cierto modo, soy «diferente», pero no diferente frente a los otros, sino diferente ante los míos: yo no hablo la lengua que hablaban mis padres, no comparto ninguno de los recuerdos que ellos hayan podido tener, ninguna cosa que les perteneciese, lo que ellos fuesen o les hiciese, su historia, su cultura, su esperanza, eso no me fue transmitido (Perec 2008, 103).

He ahí, de nuevo, la desincronización, la fisura. La marca de una sensibilidad que tiene relación y aun se ensancha con la dislocación o el desplazamiento, con el desarraigo y el estar siempre fuera de lugar. La falta de sitio, la pieza que falta para cerrar el puzzle, la incapacidad de identificarse, la desaparición,

10 Aquí tan sólo nos conformamos con recordar el comienzo del primer relato en francés de Beckett, Le Calmant: «Je ne sais plus quand je suis mort. Il m'a toujours semblé être mort vieux». Y también, que fue en Lukács en quien Perec apreció este sentido, para él «indispensable», de la noción de ironía, esto es: la distancia que el narrador puede poner entre él y sus personajes o las acciones de su relato. 
o la ausencia como marca de vida. Perec manifiesta aquí un sentimiento bien ambiguo en relación con eso que llamamos la vida cotidiana. Por una parte, una profunda sensación de pérdida y una nostalgia por una experiencia de socialización de la que ha sido apartado en su origen. Pero, a la vez -su relato lo evidencia-, una desconfianza muy intensa hacia las normas antropológicas que, como verdades de la experiencia, traza esa misma vida íntima y ordinaria. Como si, a la manera de un sufí, o de un espíritu órfico o platónico, considerase todas esas verdades como meros productos ilusorios - molestos y peligrosos- de los que sería necesario separarse.

Todo esto tiene relación, también, con la capacidad que, en tanto que extranjeros, hemos de tener para autotransformarnos y sobrevivir en condiciones ajenas de vida; en un mundo que, en definitiva, no nos contempla, porque prácticamente no existimos para él. Como ha sugerido Richard Sennett en su estudio de la figura del exiliado, es incluso posible, a la postre, que el extranjero tenga con su cultura de adopción una relación más inteligente, más comprensiva, que la persona que nunca ha salido de ella y no conoce nada más que lo que tiene delante; esto es: que no se ha visto obligada a sopesar las diferencias entre una cultura y otra (Sennet 2014, 93). De un modo ciertamente paradójico y extremo, el relato de Perec abre críticamente una fascinante derivada de esta cuestión: cómo adquirir un crecimiento de sensibilidad y producir transformaciones en uno mismo si uno no ha sido desplazado físicamente, si ha vivido siempre en la misma ciudad, incluso en los mismos lugares reducidos a un dominio verdaderamente repetitivo y estrecho: durante el día, la Ópera, el Louvre, la calle Saint Honoré con el cruce de Rue des Pyramides; por la noche: las avenidas desiertas, los cines, los grandes bulevares, «de la République a la Madeleine, de la Madeleine a la République» $(U H Q D, 26)$. Todos ellos, especialmente las salas de cine vacías que el protagonista visita, conforman un espacio negro, fundamental, iniciático: pre-natal (Daney 2001, 23). Puede que esto sólo sea posible a condición de buscar con toda conciencia la extrañeza, precisamente, el desarraigo, el desplazamiento. Romper crudamente las cadenas de las circunstancias. Una socialización completa, la integración total, sería así la base de la inanidad, cuando no de la estupidez y la entrega. Se trataría entonces de una voluntad de poder que pasa por cultivar lo que en nosotros haya de extranjeros en nuestra identidad.

Para ello, lo más habitual es pensar en un cultivo a la manera en que Sennett opta, que es coincidente con la idea romántica del sujeto como obra de arte que se construye a sí mismo: manejando creativamente la propia condición de desplazado. Tratando «los materiales de identidad de la misma manera en que un artista trata los objetos inertes que constituyen el tema de su pintura. Uno tiene que hacerse a sí mismo» (Sennet 2014, 93). Perec, por el contrario, se decide por una vía absolutamente opuesta, que es la de Kafka o Blanchot: una 
subjetividad deshaciéndose a conciencia. Como si el sujeto artista, envuelto ahora -signo de los tiempos- en una condición pop y minimalista, se dejase arrastrar y borrar en la identificación con una objetualidad tan inerte como omnipresente, invasiva. Ya no es tanto que vagando por el mundo -al modo de Edipo- uno adquiera la transformación o la expiación de sí mismo. No aparece aquí ningún dolor ante la falta de hogar -no estamos en absoluto ante una figura trágica- ${ }^{11}$, sino más bien que en esa deriva insustancial por la superficie de las cosas de la urbe uno se libera al cabo de toda participación ciega, también de toda potencia de relación. No se trata siquiera de una destrucción de los marcos de referencia sino, justamente, de su fisura o fractura. Y de la desaparición a través de ellos. De esa manera-que linda efectivamente con la apateia estoica- el sujeto cree posible alcanzar un fondo de poder superior que tiene que ver, en principio, con la adquisición de una libertad interior. En tanto que libertad independiente de toda circunstancia y lugar. Libertad que dispensa de cualquier dependencia onto-teológica: libertad moderna; que habría que poner en relación, quizás, con el principio de ausencia misma como fundamento final del devenir. Es como si la farsa o la fábula del mundo se hubiesen despojado de todas sus máscaras, dejando el rostro de su propia nulidad al descubierto ${ }^{12}$.

$\mathrm{Y}$ es que, en cierto modo, esa voz que se dirige una vez tras otra al protagonista y fija sus gestos en un orden inmutable -voz que viene de Beckett, y de Butor-, al reiterar el pronombre de segunda persona en el inicio de sus frases, adquiere una dimensión letánica, encantatoria. Voz neutra, lisa, sin ningún sentimiento, sin proximidad alguna, a menos que entendamos por ello ciertos giros irónicos. Desde luego, nada tiene que ver con la voz en primera persona que enuncia los relatos de Camus o de Sartre. Voz que en el film es la de una mujer, como si de esa forma se profundizase en la escisión, la que se abre originariamente con los géneros. Esa voz, decimos, que es la de la ley o del poder, de un poder tan lejano, pero al tiempo íntimo como inexorable, introduce como una especie de registro de reglas -¿monásticas?-. En realidad, se trata más que nada de prohibiciones, que el sujeto habrá de cumplir a rajatabla, en esa su nueva vida de anacoreta metropolitano, reducido al extremo de la absoluta pasividad. A ser un puro otro sin el poder de la palabra; alguien preverbal, incluso. Místico de la nada, efectivamente. Esa voz es importante: casi diríamos que el relato se difracta, como un monstruo mitológico, en una especie de personaje bicéfalo: entidad desdoblada, hendida entre un observado

11 Si bien la propia insistencia en el carácter incondicionado y maquinal de la decisión y los actos del protagonista del relato podría señalar, desde una perspectiva psicoanalítica, y como por inversión, la presencia de un muy profundo e irreductible trauma.

12 Éste sería, a fin de cuentas, el poder y el fundamento que reposa en la verdad final que, al parecer, comunicó en su agonía el viejo de la montaña a uno de sus discípulos, tal y como no dejaba de recordar GuyDebord: nada es verdad, todo está permitido. 
y alguien que observa, entre alguien que habla y otro que vive, entre un cuerpo y la palabra.

De hecho, las prohibiciones que la voz impone o simplemente proclama, se podrían resumir en el dictado de vivir bajo el reinado del no: una especie de severo lipograma existencial (Joly 2011, 21): «No vuelves a ver a tus amigos. No abres la puerta. No bajas a buscar el correo. No devuelves los libros que tomaste prestados de la Biblioteca del Instituto Pedagógico. No escribes a tus padres» $(U H Q D, 24)$. El modo verbal de esta voz es un presente de indicativo que, en definitiva, se confunde con un innegable modo imperativo. Como sucedía con la educación del estoico - usando una expresión de Pessoa-, aquí no se trata evidentemente de ninguna tentativa de introspección, sino de una obligación autoimpuesta; un método riguroso para cancelar, al modo por ejemplo que se asignó Marco Aurelio, determinadas actitudes o afectos o representaciones (la imaginación entre ellas). Tal cancelación habría de ser el paso preciso para alcanzar una percepción exacta de las cosas, y por tanto para obtener la virtud. Hablamos - como es sabido- de una técnica con vistas a adquirir el dominio sobre las pasiones. Un método que también conlleva el extrañamiento, pues pasa fundamentalmente por cancelar las representaciones erróneas, los postulados considerados obvios, los reconocimientos que nuestra costumbre perceptiva ha hecho comunes. Se trataría de ver las cosas como si no tuvieran sentido o estuviesen ya despojadas de él. Un modo indudablemente apocalíptico, donde el mundo también se ha vuelto por ello mismo un enigma absoluto y exterior: «Borra la imaginación -escribe Marco Aurelio-. Detén el impulso de marioneta. Circunscríbete al momento presente. Comprende lo que te sucede a ti o a otro. Divide y separa el objeto dado en su aspecto causal y material. Piensa en tu hora postrera».

Pareciera, entonces, que comprender menos es ver más, y mejor. Alcanzar una dimensión más profunda de eso que llamamos realidad. «Debes desacostumbrarte de todo» $(U H Q D, 50)$, conmina la voz, esa autoridad inmaterial que es él y no es él al mismo tiempo. Tenemos, por tanto, un hombre que se comporta como un autómata. Artefacto sumamente paradójico, en la medida en que ha sido él mismo el sujeto de la decisión, si es que esto puede en este caso decirse así, lo cual es ciertamente dudoso. Y de que ésta -la decisiónse caracteriza, fundamentalmente, por lo que conlleva de desactivación, de pasividad, de inacción. Pues el problema tal vez fundamental con que este hombre se enfrenta es, precisamente, el de alcanzar la libertad suprema -el poder absoluto- a pesar de sí mismo, o contra sí mismo. Dicho de otro modo: ¿es posible esta libertad - esta novedad absoluta- cuando uno está siempre frente a sí mismo, consigo mismo? ¿No nos encadenan nuestras tareas, nuestros hábitos, gestos, palabras y facciones a una identidad, fatalidad y angustia difí- 
cilmente superables? ¿Cómo actuar sabiéndose determinado? ¿Cómo volverse un autómata de la indeterminación?

Este carácter de negación es lo que ciertamente nos acerca a Bartleby, el personaje famoso de Melville que emerge subrepticio al final del relato: el gran separado, el héroe del no, de la renuncia y la anulación. Alguien que toma tan extraña decisión en medio, por cierto, de Wall Street, cuando este específico lugar comenzaba a ser el corazón económico del planeta. Es más, como sabemos -el propio Perec se ha encargado de decírnoslo- esta novela quiere ser una relectura del escrito de Melville. Acaso tampoco se halle lejos la huella de Wakefield, esa criatura salida de la imaginación de un íntimo amigo de Melville, el gran recluido en su dormitorio: Nathaniel Hawthorne. Como sabemos, Wakefield, nombre sintomático, relata la desventura de alguien que decide separarse del engranaje universal que forma el mundo cotidiano. En el centro mismo de Londres, se ha desvinculado del universo. Se ha desvanecido. Como un muerto-vivo, ha renunciado a su lugar en el sistema durante muchos años. De repente, una tarde, una tarde que, como en el final del relato de Perec, rompe a llover, Wakefield retorna a su hogar, que ya es, naturalmente, otro, como lo es él mismo. El destino de Wakefield, en palabras de Hawthorne, bien podría ser el del hombre que duerme: «los individuos están tan perfectamente ajustados a un sistema y los sistemas unos a otros y todos a un todo que, un hombre, al salirse del sistema por un momento, se expone al riesgo espantoso de perder su lugar para siempre. Al igual que Wakefield, se puede convertir en el Proscrito del Universo» (Hawthorne 1983, 35).

Y, sin embargo, el destino inapelable del hombre de Perec es seguir caminando, rotar dentro del gran círculo movedizo de la espera, «amnésico errante en el país de los ciegos»(UHQD, 26): «Haga buen o mal tiempo, llueva o luzca el sol -escribe Perec-sople el viento a ráfagas o no se mueva ni una hoja de los árboles, apague las farolas el alba o las encienda de nuevo el crepúsculo, ya estés perdido entre la multitud o solo en una plaza desierta, sigues caminando, sigues vagando» $(U H Q D, 63)$. Caminante solitario en medio de una plaza desierta. Como si de un autómata se tratase; un artefacto orgánico cercano en todo punto a un mecanismo de relojería. Como la máquina misma que regula el tiempo. He ahí, al fin, el modelo procedimental de este sujeto, continuamente sugerido a lo largo de todo el film y el escrito, desde la presencia de los relojes y los marcajes de la duración -el despertador, las luces de los semáforos de la Rue Saint-Honoré, el campanario de Saint-Roch, la gota que, al modo de una clepsidra, cae del grifo comunitario- hasta ese anciano petrificado que parece funcionar como un perfecto cuadrante solar en el jardín. La regla es organizar la vida como un engranaje imperturbable de relojería, «como si el mejor medio de no perderte, de no venirte abajo del todo, fuese dedicarse a tareas irrisorias, decidir todo con antelación, no dejar nada al azar. Que tu vida sea aislada, lisa, 
redonda como un huevo, que quien fije tus gestos sea un orden inmutable que decida todo por ti, que te proteja a tu pesar» (UHQD, 107-108).

Con los relojes también guarda el artista del hambre una relación particular. De él se nos dice que, cuando alcanza el límite de absorción, que se corresponde también con la mayor indiferencia hacia todo lo que lo rodea, nada ni nadie le preocupan, «ni siquiera la marcha del reloj, de tanta importancia para él». Tanto es así que el narrador se encarga de destacar que, precisamente el reloj, es la única pieza de mobiliario que el ayunador tiene en su jaula. En cierto modo, el protagonista del relato de Perec, en su afán por desdibujarse, viene a continuar la tradición de los artistas del hambre en que se inspirara Kafka. Quiere alcanzar la rígida y mecánica profesionalidad de aquellos extraños ayunadores que a finales del siglo XIX animaban las ferias populares. Vemos, pues, que todo consiste en un problema de relojeros y de engranajes: mecánica social, ocupación de un puesto en la máquina. Si te separas para comprobar en perspectiva tu lugar dentro de la ronda, pierdes el puesto, toda oportunidad: desapareces sin dejar huella. Efectivamente: la primera función de las máquinas de contar el tiempo, especialmente desde el momento en que se volvieron objetos domésticos al alcance de cualquier bolsillo burgués -en el tiempo precisamente de Bartleby o Wakefield-, no fue solamente contar el paso de las horas, sino, aún más, coordinar las acciones humanas, regular y acompasar la sinfonía social (Landes 2007 y Mayr, 2012). Esto es algo que ya notara Chesterton allá por 1908 (en el relato titulado «Una historia un tanto improbable») cuando describe a los habitantes de la City como pobres seres apresurados que no podían dejar de vigilar los movimientos de las manecillas del reloj: «todos tenían un ojo algo bizco, hipnotizado por la enorme cara del reloj de pared». Esclavos de la modernidad, como los califica el propio narrador de Chesterton, «se podía oír el tintineo de sus grilletes. Cada uno de ellos estaba, de hecho, atado a una cadena; la cadena más pesada con la que se ha esclavizado nunca al hombre: la cadena del reloj de bolsillo» (Chesterton 2008, 74). Pero esa cadena, y su condena, comenzó quizás antes: en los inicios mismos de la Modernidad, los que, por ejemplo, coinciden con el reinado del rey melancólico y escurialense, el hombre que en su escritorio regentaba el poder supremo, el rey «lecto-escritor» por excelencia. Sobre la mesa de su estudio -nos dice un erudito- «su lámpara de vela era a la vez un reloj» (De La Flor y Escandell Montiel 2014, 73).

La decisión de Wakefield, como la del protagonista de Perec o el artista del hambre, descubre algo sin embargo esencial: la experiencia del tiempo en sí, al segregarse, justamente, de toda duración socializada. El hombre que duerme aspira a ponerse en el lugar del corazón intemporal del tiempo. Como si retirándose del tiempo pudiese alcanzar su origen en una especie de absoluto. Un propósito quizás desmesurado que al cabo uno no puede soportar solo. 
De ahí su vuelta al hogar, en el caso de Wakefield. Lo que Un hombre que duerme nos relata, al cabo, es que, cuando uno se libera o se ve desprovisto del tiempo -algo en verdad imposible, pues constituye nuestro elemento vital-, entonces se encuentra sin apoyo, incapaz de distinguir entre uno y el mundo, entre los otros y su cuerpo, ni siquiera su mente. No hay nada como objeto, ni una percepción ni un pensamiento, sin que esa cosa misma se haga sentir como si fuera al tiempo uno mismo y otra cosa distinta de sí. Lo propio y lo impropio se producen en simultaneidad, y con ella, esa distinción se derrumba. Sustraído el protagonista al acoso del tiempo, a su mero ajetreo y a su pasaje, se ha fundido en peligrosa indistinción con el mundo, coincide plena y funestamente con él. Y entonces esta situación desborda y destroza cualquier tipo de experiencia o análisis. En ese momento, que la versión fílmica presenta con gran plasticidad, París se convierte en una ciudad fantasmal y desierta, como un avatar contemporáneo y apocalíptico de Brujas la muerta o una procesión de espectros de Munch. Con todo (lo) presente tomado por el tedio o el hastío, el famoso spleen baudeleriano en que el sujeto se siente atrapado en la cárcel de su lograda insensibilidad. Él ha alcanzado el punto final de una inmersión, una inmersión consciente, a conciencia, en la inconsciencia misma. Y en ella se deja estar, hasta hundirse. Diríamos incluso, en este punto, que el spleen es la nostalgia insatisfecha de sentir otra vez el tiempo mismo. Walter Benjamin sugirió algo parecido, cuando definió el término como el sentimiento que corresponde, incesante, a la catástrofe (Benjamin 2013, Vol.1, 556). Donde catástrofe ha de entenderse más bien en su sentido etimológico: como ruptura del ritmo o del pulso estrófico. Esto es: caída del, desde el tiempo. Como una fisura, como una cesura, algo se ha roto en la línea de la temporalidad (Agamben 1989). ${ }^{13}$ Conviene leer desde esta perspectiva la omnipresente figura de la falla en la pared, o de la fractura en el espejo, incluso la cicatriz en el rostro -en el labio- del protagonista del relato y el film de Perec.

No olvidemos, sin embargo, tan pronto a Giacometti, él también en cierto modo un bartleby, en el sentido, ya famoso, de Vila-Matas. Un hombre condenado como por un destino aciago a un eterno inacabamiento, en su insatisfacción permanente y diaria. En su recomenzar una vez tras otra la misma figura. Él también un separado, un marginado voluntario de todo circuito social. Capaz, precisamente por su separación, de contemplar sin velos el espectáculo de la ciudad, con sus espacios y sus plazas, sus cuerpos, sus transeúntes: «Esas

13 Hölderlin se interesó vivamente por el valor filosófico-literario de la cesura, como marca precisamente de una catástrofe con que se rompe el tiempo de la dicción del poema, no ya solo como lo que él mismo denominó «interrupción contrarrítmica», sino como una suerte de negación ontológica que el poema mismo debe pronunciar y sobrellevar. Esta cesura es, a juicio de Deleuze, el hombre mismo: cesura en el tiempo. (Sobre esto, cf. Agamben 1989). 
personas que corrían de un lado para otro en la calle eran autómatas inconscientes -apunta el escultor-, recordaban a las hormigas, cada uno por su camino; totalmente solos, hacia una meta desconocida para los demás. Los unos junto a los otros sin mirarse. O volviéndose para mirar a una mujer» (Giacometti 1990, 448). En este aspecto, la inquisición perecquiana es idéntica al enigma que intriga al escultor, el que ya había intrigado a Poe, por cierto:

Operarios que pasan como un relámpago, ¿convocados por qué emergencia? No sabes nada de las leyes que hacen juntarse a esas personas que no se conocen, que no conoces, en esta calle a la que vienes por primera vez en tu vida y donde no tienes nada que hacer salvo mirar a esta multitud que va y viene, se precipita, se para: esos pies sobre las aceras, esas ruedas sobre la calzada, ¿qué hacen? ¿Adónde van todos? ¿Quién los convoca? ¿Quién los hace volver? ¿Qué fuerza o qué misterio les hace posar alternativamente el pie derecho y luego el izquierdo sobre la acera con, además, una coordinación que difícilmente podría ser más eficaz? Miles de acciones inútiles confluyen en el mismo instante en el campo demasiado estrecho de tu mirada casi neutra (UHQD, 53).

El París de Perec o de Giacometti es el laboratorio, el hormiguero, la gran metrópolis de las multitudes anónimas: el seno inmenso que envuelve a todos con la misma indiferencia, sin elegir, sin prejuzgar. Podría muy bien ser Londres, el Londres de Hawthorne o de Thomas De Quincey, por ejemplo, o el Nueva York de Bartleby. No es más que el laberinto babélico con sus criaturas, sean estas hormigas, hombres o ratones, hombres como ratones, según la voz que narra en $U H Q D$. La gran máquina, el experimento moderno, en fin, cuyos movimientos atropellados, intermitentes, repetitivos, trató de analizar Poe, en El hombre de la multitud. O también: el trasiego estúpido y fascinante de las filas atropelladas de curiosos que desfilan ante la jaula del artista del hambre y que, inopinadamente, un día nefasto dejan de sentir atracción por su espectáculo sutil, para pasar a hacinarse delante de otras diversiones. Regidos sabe dios por qué inescrutables destinos. Ya Walter Benjamin, en su Obra de los pasajes advirtió que los movimientos de esos seres de la multitud no son tanto de ellos mismos como «de las máquinas que de ellos se sirven» (Benjamin 2013, J 60 a, 6). Para acabar viendo en el narrador del cuento de Poe tal vez la figura primera del flâneur, en la medida en que, desde la lejanía va observando los gestos y las reacciones de esa masa de seres; sin compartir, no obstante, su actitud. El flâneur es el gran separado, él vive, por decir así, en un santo y continuo extrañamiento. Su pasividad consiste en haberse reducido a ser pura y restringida inacción visual: «Más bien parece -concluye Benjamin-que se desconecta; su ir sereno sería no otra cosa que protesta inconsciente contra el 
tempo del proceso productivo» (Benjamin 2013, J $60 \mathrm{a}, 6)^{14}$. Como un ectoplasma inadvertible, este hombre -silueta anestesiada, entidad de mirada anestética- debería fundirse en el escenario de cemento y muros descoloridos de la gran ciudad, al modo de un Bartleby pintado por Magritte, o como el cuerpo del artista del hambre desahuciado e inapreciable para la masa. Diríamos que comparte la misma dialéctica ya puesta en obra por El hombre de la multitud de Poe, aquélla que, de nuevo Benjamin -siempre Benjamin-sacara a la luz: «Dialéctica del flâneur: por una parte, el hombre que se siente observado por todo y por todos, lo que es como decir: el sospechoso; de otra, el inencontrable y escondido» (Benjamin 2013, M 2, 8). Efectivamente, silueta convertida en polvo, diríamos incluso que se ha vuelto nada más que un lugar. Un lugar traslúcido. «Lugar ocupado al que nadie se acerca» $(U H Q D, 98)$. Alguien, decididamente, inaccesible.

Acabemos, sin embargo, con Giacometti y sus hombres que caminan. No me parece para nada irrelevante la siguiente declaración de Georges Sadoul, donde decreta un origen inesperado de esta figura idiosincrásica del escultor: «Trabajé - dice Sadoul- con Giacometti en un número especial de Labyrinthe, que publicaba entonces el editor Skira. En primera página habíamos reproducido El hombre que camina, de Marey. Esta cronofotografía de 1885 impresionó mucho a Giacometti y le dio el tema de varias de sus más bellas esculturas de la posguerra, como aquélla donde cinco hombres se cruzan») (Giacometti 1990, 450). No podía haber mejor referencia, dado que en la pieza de Marey contemplamos propiamente la manifestación más evidente del hombre anónimo que camina por la gran ciudad: el hombre cualquiera que, si queremos, y no por casualidad, está -al modo de Deleuze- en las raíces mismas del cine. Deberíamos comparar esta imagen con otra-casi contemporánea- de Rodin, con el mismo tema: el hombre que marcha. Ambas pretenden reconstituir el movimiento de alguien que camina, pero de manera ciertamente diferente. Rodin se sirve de una pose, un posicionamiento privilegiado que resume o condensa la información más completa o significativa de un fenómeno, en este caso: el acto de caminar. Por el contrario, Marey, como a juicio de Bergson hace la ciencia moderna, actúa seleccionando en su análisis del movimiento una serie indiferenciada a partir de un instante o de un momento cualquiera. En su reconstitución del movimiento ya no hay ningún privilegio de un momento determinado o de una pose sobre otra. ¿Qué quiere decir el instante cualquiera? Quiere decir, justamente, instantes equidistantes, tal cual los

14 No puedo dejar de ver aquí, de nuevo, el propio proyecto creativo de Giacometti, sometido por él mismo a una duración inusitada y siempre imprevisible. Y hasta su deriva vital, tan conocida por sus votos de pobreza, su humildad, su modestia extrema, su rechazo casi absoluto a todo. 
marca una máquina, un reloj. No quiere decir todos los instantes, quiere decir cualquiera, a condición de que sean equidistantes. Lo que Marey inventa, lo que será luego la base misma de la imagen cine, es la equidistancia de los instantes fotografiados. Y lo que tenemos como resultado de este proceso ya no es una figura relacionada con un momento privilegiado, o con una información sustancial como forma de condensación de un fenómeno, sino el fenómeno mismo desplegado en la forma de una trayectoria. Ya no tenemos, pues, una forma, tenemos una cronografía, o, en palabras de Deleuze: «una ecuación, y una de las maneras de definir una ecuación es precisamente la determinación de una figura en función del instante cualquiera que concierne a la trayectoria que describe esa figura» (Deleuze 2009, 33).

¿Cómo sorprendernos ahora de que el hombre de Marey, el hombre que camina, sea la consagración de ese hombre cualquiera notado por Poe que se funde con la multitud, y lo hace en tanto que se ha vuelto un número, un puro o mero número en la masa cuya vida puede resumirse al modo de una trayectoria dibujada por la sucesión maquinal de instantes cualquiera? Trayectoria incluso mensurable y con posibilidad de replicación en lo que tiene de fundamentación numérica: cronográfica, ecuacional. Mundo mecanizado, plano, planificado: de él es posible ya realizar un compendio sin apelar a ningún momento o singularidad privilegiada, sin destacar ningún vértice de intensidad. Recurriendo tan sólo a designar la relación entre dos instantes cuyo carácter es el de ser equidistantes entre sí y de otro instante. Mundo, pues, sin épica y sin tragedia-campos éstos que dependían y se reconstituían a partir de los momentos privilegiados-. ${ }^{15}$ Universo chato, sin aura, mundo-engranaje, mundo-máquina o reloj. Prosaísmo de novela, de la vida cotidiana sometida a los ritmos de la mercancía y el consumo.

En este sentido, y para acabar al menos por el momento, diremos que, tal vez, la práctica de la deriva y el desvío literario, la experimentación lipogramática y los recuerdos colectivos, la exploración de todos los quiebros del lenguaje y de lo infraordinario en Perec están sustentados por una causa común: la tentativa - incumplida, me temo: Un hombre que duerme es el relato de una desilusión, dijimos- de poder captar un espacio y una experiencia anteriores a todos los señuelos de la mercancía y del trompe l'oeil con que nos fascina la industria del consumo o la escenografía de lo espectacular; con que están construidas y regladas o reguladas día a día nuestras vidas. Lo infraordinario sería, utilizando las palabras de Lefebvre, el alcance de lo cotidiano eludiendo la cotidianeidad. Retomar quizás un semblante o encontrar el pasaje, al fin, en

15 Con lo que vemos cómo la disciplina anacorética trataba de constituir una huida de ese mundo épico o trágico, por medio precisamente del rasurado de todo momento fuerte o privilegiado, a través de la aniquilación por igualación y regla de toda singularidad. 
que poder reconocerse antes de toda diferenciación. De las diferenciaciones de todo tipo, como las de la palabra, las de la comida, los gustos, los saberes, el pensamiento. Espacio efectivamente infraordinario, pues reposa siempre como en la igualdad absoluta del antes o de la noche que suspende el tiempo de la determinación y la diferencia. La noche que abre, en fin, la posibilidad de escapar a las estrategias de la vigilancia. ¿No funciona, en este sentido, el proceso de extrañamiento mismo del que hablaran los formalistas rusos como una desfamiliarización que comienza por liberar a la prosa del mundo, la propia comunicación lingüística cotidiana, tornándola ahora perceptible en tanto que específica construcción verbal, liberándola de toda tendencia a la automatización, a la economía de medios, a la rutina, en fin, que domina el prosaísmo moderno?

Sucedió un momento en que el mundo mismo se volvió, para Perec, un gran texto. Por eso él hubo de someter los espacios, los hábitos y las construcciones a ese mismo proceso de desfamiliarización. Perec no cesó de inventar reglas para deshacer esos campos fijados: el de lo social y el del lenguaje y lo literario. Entonces, ese nuevo texto poético urbano solicita que la percepción del lector se fije en él, en él mismo, para tratar de lograr, quizás, a través de esa ruptura con la forma de percepción habitual impuesta por la experiencia del día a día, una nueva provisión de montaje de la realidad. Este juego o este procedimiento, esta suma de procedimientos permitiría abrir como una reserva donde todos aún seríamos iguales, sin propiedades. Un acceso - otro-a lo real: es la reserva de lo que siempre está debajo y no se deja captar por nada, pues nada lo justifica o da causa y razón de ello; sustancia infra, anterior - no sometida al accidente ni atributo- o ruido de fondo que no se vincula a nada, salvo a sí mismo. Anterioridad en la que por ejemplo se halla el durmiente, los durmientes. En el antes de cualquier distinción y cualquier separación, cualquier discernimiento de persona y de sentido. De todo ese mundo en letargo, Un hombre que duerme tan sólo nos ofrece su momento negativo, el procedimiento que consiste en negar la forma y los modos: la prosa imperante -imperativa-del mundo. Como mucho, dibuja el tiempo de espera que consiste en deponer las posiciones, desarmar los sistemas de activación, desconectar las relaciones y aumentar la dificultad y la duración de la percepción misma, negando sus finalidades, sus utilidades, su instrumentación. Pero es una tentativa que ha conducido, sin embargo, al colapso. Al momento peligroso y ambiguo donde, perdido todo pie o todo hilo, todo se irrealiza en uno y las cosas se presentan a un tiempo amenazantes y gravosas, como presencias insidiosas dentro de uno y a la vez fantasmagóricas, con la familiaridad insoportable de lo insólito. Un sueño de poder a todas luces aciago, quizás tan sólo pura negación. El hombre que duerme ha buscado, como el artista del hambre, la perfección en la privación: anhela la plenitud del ayuno social. Sueña por tanto lo imposible: una ausencia sin 
negatividad. Es evidente que todavía no ha llegado el momento saludable de la rememoración o el despertar, la precisa visión y dicción de lo inmemorial, lo igual decisivamente para todos, la revelación suave de lo indistinto.

\section{REFERENCIAS BIBLIOGRÁFICAS}

agamben, G. 1989: Idea de la prosa. Barcelona: Ed. Península, tr. de Laura Silvani. BECKETT, S. 1989: Mercier y Camier. Barcelona: Editorial Lumen.

Benjamin, W. 2013: Obra de los pasajes. Madrid: Abada Editores, tr. de Juan Barja. Chesterton, G. 2008: Tratado elemental de demonología. Córdoba: Ed. El olivo azul, tr. y notas de Diana Pérez García.

DANeY, S. 2001: La maison cinéma et le monde, I. Le Temps des Cahiers 1962-1981. Paris: P.O.L.

DEBORD, G. 1994: Oeuvres cinématographiques complètes. Paris: Gallimard.

DEBORD; G. 1999: «Perspectivas de modificación consciente de la vida cotidiana», en Internacional Situacionista. Vol. 1. La realización del arte. Madrid: Ed. Literatura Gris.

DE LA FLOR, F. y eSCANDELL MONTIEL, D. 2014: El gabinete de Fausto. 'Teatros' de la escritura y la lectura a un lado y otro de la frontera digital. Madrid: Consejo Superior de Investigaciones Científicas CSIC.

Deleuze, G. 2009: Cine I. Bergson y las imágenes. Buenos Aires: Ed. Cactus, tr. de Sebastián Puente y Pablo Ires.

DE QUINCEY, TH. 2001: Confesiones de un inglés comedor de opio. Madrid: Ed. Valdemar, trad. de José Rafael Hernández Arias.

ELIOT, T.S. 2001: La tierra baldía. Cuatro Cuartetos y otros poemas. Barcelona:Círculo de Lectores, ed. bilingüe de Juan Malpartida y Jordi Doce.

flaubert, G. 1989: Cartas a Louise Colet. Madrid: Ed. Siruela, tr. de Ignacio Malaxecheverría.

GAYA, R. 2010: «El Escorial», en Balcón Español, Obra Completa. Valencia: Ed. Pretextos.

GIACOMETTI, A. 1990: Dibujo, escultura, pintura. Madrid: CARS-Lunwerg.

GINZBURG, C. 2000: Ojazos de madera. Nueve reflexiones sobre la distancia. Barcelona:

Ed. Península, tr. de Alberto Claverí.

HAWTHORNE, N. 1983: El gran rostro de piedra. Madrid: Ediciones Siruela, tr. Federico Eguiluz.

JOLY, J.-L. 2011: «Des choses qui dorment», en Roman 20-50. Revue d'étude du roman XXe siècle. Georges Perec. Les Choses et Un hommequidort, No 51, juin 2011; 
pp. 11-26.

LANDES, D. 2007: Revolución en el tiempo. Madrid: Ed. Crítica.

LEFEBVRe, H. 1972: La vida cotidiana en el mundo moderno. Madrid: Alianza Editorial, tr. de Alberto Escudero.

MAYR, O. 2012: Autoridad, libertad y maquinaria automática en la primera modernidad europea. Barcelona: Ed. Acantilado.

NANCY, J.-L. 2003: El sentido del mundo. Buenos Aires: Ed. La Marca, tr. de Jorge Manuel Casas.

NANCY, J.-L. 2007: Tumba de sueño. Buenos Aires: Ed. Amorrortu, tr. de Horacio Pons.

PEREC, G. 1989: Un hombre que duerme. Madrid: Ed. Impedimenta, tr. de Mercedes Cebrián.

PEREC, G. 2008: «Ellis Island», en Nací. Madrid: Abada, tr. de Diego Guerrero.

Proust, M. 2004: Por el camino de Swann, en Obras Completas I. Madrid: Ed. Aguilar, tr. de Pedro Salinas.

SENNETt, R. 2014: El extranjero. Dos ensayos sobre el exilio. Barcelona: Ed. Anagrama, tr. de Marco Aurelio Galvarini.

RANCIÈRE, J. 2015: Aisthesis. Escenas del régimen estético del arte. Santander: Shangrila textos aparte, tr. de Mariel Manrique y Hernán Marturet.

TODorov, T. 1965: Théorie de la littérature. Paris: Ed. du Seuil.

Alberto Ruiz de Samaniego es Profesor titular de Estética y Teoría de las Artes en la Universidad de Vigo. 
